\title{
REMOVAL OF METAL IONS FROM AQUEOUS SOLUTIONS USING CROSSLINKED POLYETHYLENE-GRAFT- POLYSTYRENE SULFONIC ACID ADSORBENT PREPARED BY RADIATION GRAFTING
}

\author{
MOHAMED MAHMOUD NASEF ${ }^{a^{*}}$, HAMDANI SAIDI ${ }^{a}$, ZAINI UJANG ${ }^{b}$ AND \\ KHAIRUL ZAMAN MOHD DAHLAN
}

\begin{abstract}
anstitute of Hydrogen Economy, Faculty of Chemical Engineering, Universiti Teknologi Malaysia, 81310 UTM Skudai, Johor, Malaysia, ${ }^{b}$ Institute of
Environmental and Water Resources Management, Universiti Teknologi Malaysia, 81310 UTM Skudai, Johor, Malaysia

${ }^{c}$ Radiation Processing Technology Division, Malaysian Nuclear Agency, Bangi, 43000 Kajang, Selangor, Malaysia
\end{abstract}

(Received: July 19, 2010 - Accepted: August 31, 2010)

\begin{abstract}
Crosslinked polyethylene-graft-polystyrene sulfonic acid (PE-g-PSSA) adsorbent prepared by simultaneous radiation induced grafting of styrene/divinyl benzene (DVB) mixture onto low density polyethylene (PE) film followed by sulfonation was investigated for the adsorption of $\mathrm{Co}$ (II), $\mathrm{Cu}$ (II), $\mathrm{Ni}(\mathrm{II}), \mathrm{Pb}$ (II) and $\mathrm{Ag}(\mathrm{I})$ ions from aqueous solutions on batch process basis. The effects of treatment parameters such as contact time, initial metal ion concentration, $\mathrm{pH}$ and temperature of the solution, on the adsorption capacity of the membrane were studied. The adsorption capacity of metal ions were found to be strongly dependent on the initial metal ion concentration and $\mathrm{pH}$ of adsorption medium and increased in the order of $\mathrm{Ni}(\mathrm{II})>\mathrm{Co}$ (II) $>\mathrm{Cu}(\mathrm{II})>\mathrm{Pb}(\mathrm{II})>\mathrm{Ag}(\mathrm{I})$. $\mathrm{Langmuir}$ isotherm model was found to be more fitting to the adsorption equilibrium data of all metal ions than Freundlich isotherm model. The adsorption kinetics of all tested metal ions was found to follow the pseudo-first order kinetic model. The membrane showed an interesting stability represented by five repeated adsorption/desorption cycles of heavy metal ions without any significant loss in its adsorption capacity. It can be suggested that crosslinked PE-g-PSSA membrane obtained in this work can be effectively used for the adsorption of heavy metal ions from aqueous solutions and the preference order is $\mathrm{Ni}(\mathrm{II})>\mathrm{Co}$ (II) $>\mathrm{Cu}$ (II) $>\mathrm{Pb}$ (II) $>\mathrm{Ag}$ (I) .
\end{abstract}

Keywords: radiation induced grafting, crosslinked sulfonic acid adsorbent, adsorption equilibrium, adsorption kinetics, removal of heavy metal ions.

\section{INTRODUCTION}

Heavy metal ions existing in wastewater streams of various industries such as electroplating, mining operations, battery manufacturing and tannery fabrication are posing environmental-disposal problems due to their nondegradable and persistence nature. Leaking of these toxic heavy metals to the soil contaminates groundwater and surface water leading to adverse effects on the health of human and animals in addition to marine life [1]. Treatment of large volumes of wastewater containing low concentrations of heavy metals pollutants is becoming increasingly important as the discharge regulations become more stringent [2]. The harmful heavy metals ions associated with various industrial activities include $\mathrm{Ni}(\mathrm{II}), \mathrm{Cr}(\mathrm{III}), \mathrm{Co}(\mathrm{II}), \mathrm{Cd}(\mathrm{II}), \mathrm{Pb}(\mathrm{II})$, $\mathrm{Mn}(\mathrm{II}), \mathrm{Cu}(\mathrm{II}), \mathrm{Zn}(\mathrm{II}), \mathrm{Fe}$ (III), $\mathrm{Hg}(\mathrm{II})$ and $\mathrm{Ag}(\mathrm{I})$.

Various technologies have been applied for the treatment of heavy metals contaminated waste streams over the past few decades. These technologies include chemical precipitation, ion exchange, membrane filtration, carbon adsorption, co-precipitation/adsorption and reverse osmosis. Each technology has its merits and limitations in application [3]. In this regard, tremendous efforts have been made to apply various biomass and natural materials as low cost adsorbents for heavy metal removal from wastewater, which recently reviewed by Gupta et al [4].

Among all, ion exchange method and its associated electrochemical applications have been successfully used in many industries for the removal of heavy metals from waste streams of various characteristics [5]. This was prompted by its heavy metal removal effectiveness especially when large volumes of waste water containing trace quantities are treated in addition to its simplicity and suitability for operation under a wide range of variable reaction conditions. Most of ion exchange processes use selective chelating/ ion exchange resins possessing anion functional groups having affinity towards heavy metal ions [6].

Cation exchange membranes are promising alternative form of chelating resins that can be effectively used for removal of heavy metal ions from water and waste water streams [7]. This is because they are not compressible and can eliminate internal diffusion limitations caused by resins using a flow-by mode [7]. Preparation of these membranes requires grafting of functional ionizable groups such as $\mathrm{SO}_{3}^{-}$or $\mathrm{COO}^{-}$on a trunk polymer, which has to be subsequently shaped into a thin foil. Radiation induced grafting (RIG) method is an attractive technique to develop tailor-made cation exchange membranes through imparting functional characteristics of a monomer to a pre-existing polymer already in a film form and consequently avoiding shaping problem. This method allows a close control over the content of the grafted moiety and properties of the obtained membrane through variation of the grafting conditions [9].
Numerous studies have been reported on preparation of cation exchange membranes by RIG using various acrylic or vinyl monomers and polymer films combinations. Grafting of acrylic monomers directly confers ionic characters to polymer films whereas, grafting of vinyl monomers requires a postgrafting chemical treatment to convert the grafted films into cation exchange membranes. The stability of these membranes relies strongly on the nature of starting film. Among polymers, polyethylene (PE) films have been frequently used as a substrate for preparation of various ion exchange membranes. This is because of PE saturated structure, cheapness, resistance to solvents, high radiation resistance and excellent mechanical properties. A comprehensive review on the use of RIG for preparation of cation exchange membranes based on PE and other polymer films for various applications can be found in references [9] and [10].

Recent studies (e.g. references: 10-12) on preparation of heavy metal ions adsorbents bearing functional groups by radiation induced grafting of a variety of monomers or monomer/comonomer combinations onto polymer substrates of various physical (fibers and films) forms for removal of some heavy metal ions from aqueous solution have showed interesting separation properties [1113]. However, the obtained adsorbents were not crosslinked and their stabilities upon regeneration (number of adsorption/desorption cycles) together with the over suitability for practical applications of heavy metal ion removal under various conditions were not investigated.

In previous studies we reported on preparation of non-crosslinked cation exchange membranes by radiation grafting of styrene onto low density PE films followed by sulfonation reaction $[14,15]$. The chemical, thermal and structural behaviors of the membranes were also investigated [16]. The obtained membranes were found to have a very good combination of physical and chemical properties promoting their use for heavy metal removal from waste water.

The objective of the present study is to investigate the potential use of polyethylene- $g$-polystyrene sulfonic acid (PE- $g$-PSSA) adsorbent obtained by radiation grafting after being crosslinked with divinylbenzene (DVB) for adsorption of $\mathrm{Ni}(\mathrm{II}), \mathrm{Co}(\mathrm{II}), \mathrm{Pb}(\mathrm{II}), \mathrm{Cu}(\mathrm{II})$ and $\mathrm{Ag}(\mathrm{I})$ from there aqueous solutions under various treatment parameters including contact time, initial concentration of the feed solution, $\mathrm{pH}$ of the adsorption medium and temperature of the solution using a batch process. The obtained data was fit to relevant kinetic and isothermal models to elucidate the dynamics and equilibrium of the adsorption of such heavy metals.

Material and chemicals

\section{EXPERIMENTAL}

Low density PE film of $60 \mathrm{~mm}$ thickness was obtained from Al-Nasr Co. Styrene of purity more than $99 \%$ and divinylbenzene, DVB, $(65 \%$ in 
ethylvinylbenzene) were purchased from Fluka and used without further purification. Chlorosulfonic acid of analytical grade (Fluka) was used for sulfonation. Solvents such as toluene (J.T. Baker) 1,2-dichloromethane (J.T. Baker) and 1,2-dichloromethane (Fluka) were reagent grades and used as received. Metal salts: nickel nitrate (Merck), cobalt nitrate (Fluka), cadmium nitrate (Merck), lead nitrate (Merck), copper nitrate (Hamburg Chemicals) and sliver nitrate (Merck) were reagent grade and used in without further purifications. Deionized water (DI) (18 M , Millipore) was used in dilution in all experiments.

\section{Adsorbent Preparation}

Samples of PE film of $5 \mathrm{~cm} \times 5 \mathrm{~cm}$ were cleaned with acetone and vacuum dried. The samples were then placed in a glass ampoule containing styrene monomer ( $50 \mathrm{vol} \%$ ) diluted in benzene. DVB was added to the grafting mixture at a concentration of $4 \mathrm{vol} \%$ and the air was removed by flushing the ampoule with purified $\mathrm{N}_{2}$ for $10 \mathrm{~min}$. The ampoule was then tightly sealed and irradiated using g-rays form a Co-60 source having a $1.32 \mathrm{kGy} / \mathrm{h}$ dose rate for $24 \mathrm{~h}$. After completion of the reaction, the grafted films were extracted, washed with toluene and soaked therein overnight to remove the excess monomer and homopolymer from the film surfaces. The degree of grafting was gravimetrically determined as the percentage of weight increase in PE films after grafting reaction using the following equation:

$$
\text { Degree of grafting }(\%)=\frac{\mathrm{W}_{\mathrm{g}}-\mathrm{W}_{0}}{\mathrm{~W}_{0}} \times 100
$$

where, $\mathrm{W}_{0}$ and $\mathrm{W}_{\mathrm{g}}$ are the weights of original and grafted PE films, respectively.

The grafted PE samples were sulfonated in a mixture composes of 10 parts chlorosulfonic acid in 90 parts of 1,2-dichloromethane (v:v) per $2 \mathrm{~h}$ at room temperature using a method described in a previous communication [15]. The sulfonated adsorbent was washed with DI water four times and hydrolyzed with $0.5 \mathrm{M} \mathrm{KOH}$ solution for $16 \mathrm{~h}$ followed by regeneration into an acid form by boiling with $1 \mathrm{M} \mathrm{HCl}$ per $2 \mathrm{~h}$. The adsorbent was then washed acid free with DI water four times before drying and storing in dark containers.

The introduction of crosslinked polystyrene and subsequent sulfonation to PE film was confirmed by Fourier transform infrared (FTIR) spectral analysis performed on a Perkin Elmer (Spectrum 2000 Explorer) spectrophotometer.

The ion exchange capacity, equivalent weight, water uptake and degree of hydration of the adsorbent in film form were determined following the procedure reported in reference [15]. The thickness of the membrane in dried form was determined using water a digital thickness gauge (Mitutoyo, Japan).

\section{Preparation of metal ion solutions}

Standard metal ion solutions of $\mathrm{Ni}(\mathrm{II}), \mathrm{Co}(\mathrm{II}), \mathrm{Pb}(\mathrm{II}), \mathrm{Cu}(\mathrm{II})$ and $\mathrm{Ag}(\mathrm{I})$ were prepared by carefully dissolving the desired amount of respective metal nitrate salt in a $100 \mathrm{ml}$ of DI water in a volumetric flask followed by dilution to $1000 \mathrm{ml}$. Stock solutions of each metal ion in concentrations in the range of $0.2-2.0 \mathrm{mg} / \mathrm{L}$ were prepared.

\section{Batch adsorption equilibrium experiments}

The adsorption equilibrium experiments of $\mathrm{Ni}(\mathrm{II}), \mathrm{Co}(\mathrm{II}), \mathrm{Pb}(\mathrm{II}), \mathrm{Cu}(\mathrm{II})$ and $\mathrm{Ag}(\mathrm{I})$ were performed using a batch process to determine the amount of metal ion adsorbed under by PE- $g$-PSSA adsorbent samples under the effect of contact time, initial feed concentration of metal ions, $\mathrm{pH}$ and temperature of adsorption medium. All the experiments were repeated three times and average values of data were calculated to ensure accuracy.

\section{Adsorption procedure}

Dried adsorbent samples were equilibrated in a series of aqueous solutions $(100 \mathrm{ml})$ placed in conical flasks containing different amounts of each metal $(0.2-2.0 \mathrm{mg} / \mathrm{L})$ at a constant $\mathrm{pH}$ of 6.6 , which was adjusted with $1 \mathrm{M} \mathrm{HNO}_{3}$ or $1 \mathrm{M}$ $\mathrm{NaOH}$ solution at the beginning of each experiment (not controlled afterwards) at $25^{\circ} \mathrm{C}$. The flasks were magnetically agitated at a constant speed of $600 \mathrm{rpm}$ for $30 \mathrm{~min}$. The adsorbent samples were removed and the concentrations of the metal ions in the remaining solutions were determined using an atomic absorption (Hitachi Z-5000 Polarized Zeeman) spectrophotometer. The amount of metal ions adsorbed per unit mass of the adsorbent and the percentage of adsorbed metal ions were obtained using equations 2 and 3 , respectively.

$$
q_{e}=\frac{V\left(C_{o}-C_{e}\right)}{w}
$$

where, $q_{e}$ is the amount of adsorbed metal ion at equilibrium (metal adsorption capacity) in $\mathrm{mg} / \mathrm{g}, V$ is the volume of the adsorption medium in liter, $C_{o}$ is the initial metal ion concentration in $\mathrm{mg} / \mathrm{L}, C_{e}$ is the equilibrium metal ion concentration in $\mathrm{mg} / \mathrm{L}$ and $\mathrm{w}$ is the dry weight of the membrane in grams.

$$
\% \text { adsorbed metal ion }=\frac{C_{o}-C_{f}}{C_{o}}
$$

where, $C_{f}$ is the final metal ion concentrations in the adsorption medium in $\mathrm{mg} / \mathrm{L}$.

\section{Effect of initial feed concentration of metal ions}

A fixed number of the adsorbent samples were rinsed in a series of metal ion solutions with concentrations varying in the range of $0.2-2.0 \mathrm{mg} / \mathrm{L}$ for $\mathrm{Ni}(\mathrm{II}), \mathrm{Co}(\mathrm{II}), \mathrm{Pb}(\mathrm{II}), \mathrm{Cu}(\mathrm{II})$ and $\mathrm{Ag}(\mathrm{I})$ and magnetically agitated at a speed of $600 \mathrm{rpm}$ for $30 \mathrm{~min}$. The $\mathrm{pH}$ of the medium was adjusted at a value of 6.6 at the beginning of the experiments.

\section{Effect of $\mathrm{pH}$ of sorption medium}

$\mathrm{pH}$ dependent metal adsorption was performed by equilibrating adsorbent samples in a series of $100 \mathrm{ml}$ solutions of $\mathrm{Ni}(\mathrm{II}), \mathrm{Co}(\mathrm{II}), \mathrm{Pb}(\mathrm{II}), \mathrm{Cu}(\mathrm{II})$ and $\mathrm{Ag}(\mathrm{I})$ with concentrations of $1.0 \mathrm{mg} / \mathrm{L}$ at various $\mathrm{pH}$ values in the range of 3.1-6.6. The $\mathrm{pH}$ of the solutions was adjusted to a desired value by adding $1 \mathrm{M}$ $\mathrm{HNO}_{3}$ or $1 \mathrm{M} \mathrm{NaOH}$ solution and magnetically agitated at a constant speed of $600 \mathrm{rpm}$ for $30 \mathrm{~min}$ at the beginning of the experiments.

\section{Desorption of metal ions and membrane reusability}

The metal ions loaded PE- $g$-PSSA adsorbent samples were rinsed in a desorption medium of $100 \mathrm{ml}$ of $0.1 \mathrm{M}$ of $\mathrm{HNO}_{3}$ magnetically agitated at a constant speed of $600 \mathrm{rpm}$ for $16 \mathrm{~h}$ at $25^{\circ} \mathrm{C}$. The adsorbent samples were removed and washed with DI water several times before subjected again to metal adsorption treatment. The adsorption/desorption process were repeated for five cycles.

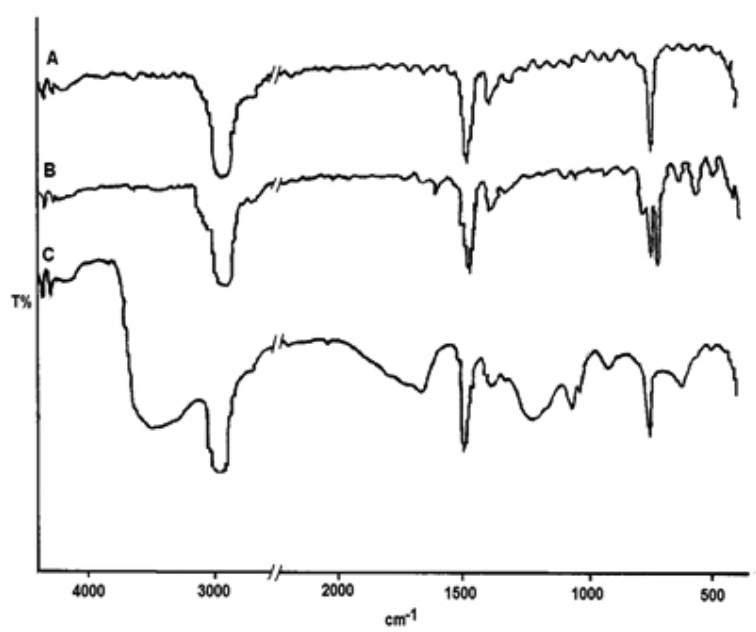

Fig.1: FTIR spectra of: A) original PE film, b) polystyrene grafted and crosslinked PE film and C) crosslinked PE-g-PSSA adsorbent film.

Table 1: Physico-chemical properties of DVB crosslinked PE-g-PSSA adsorbent film with a degree of grafting of $66 \%$.

\begin{tabular}{|l|c|}
\hline Properties & Values \\
\hline DVB content $(\mathrm{vol} \%)$ & $4.0^{\mathrm{a}}$ \\
\hline Thickness $(\mu \mathrm{m})$ & 75.0 \\
\hline Water uptake $(\mathrm{wt} \%)$ & 58.0 \\
\hline Ion exchange capacity $(\mathrm{mmol} / \mathrm{g})$ & 2.7 \\
\hline Hydration no. $\left(n \mathrm{H}_{2} \mathrm{O} / \mathrm{SO}_{3}^{-}\right)$ & 23.0 \\
\hline Equivalent weight $\left(\mathrm{g} / \mathrm{mmol}^{-}\right)$ & 370 \\
\hline
\end{tabular}

${ }^{a}$ Value of DVB content in grafting solution 


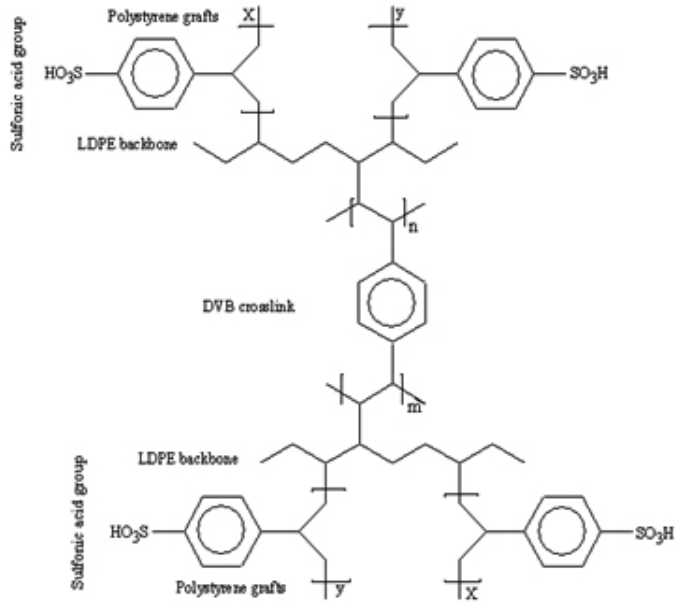

Fig. 2: Tentative molecular structure of DVB crosslinked PE-g-PSSA adsorbent film.

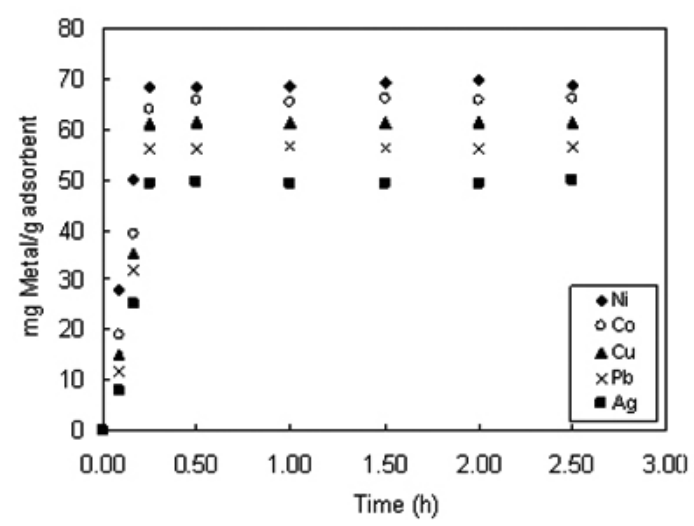

Fig. 3: Time courses for adsorption of heavy metal ions on crosslinked PE- $g$-PSSA adsorbent. Adsorption conditions: initial concentration, $1.0 \mathrm{mg} / \mathrm{L}$; adsorption medium volume, $100 \mathrm{ml}$; agitation rate, $600 \mathrm{rpm}$; temperature $25^{\circ} \mathrm{C}$ and $\mathrm{pH}, 6.6$.

\section{RESULTS AND DISCUSSIONS}

DVB crosslinked PE- $g$-PSSA adsorbent with a degree of grafting of $66 \%$ was prepared, cut into strips and used in adsorption studies in this work. Fig. 1 shows typical FTIR spectra of original PE film, polystyrene grafted/crosslinked PE film and crosslinked PE- $g$-PSSA adsorbent. The introduction of crosslinked polystyrene grafts was observed (in spectrum B) from the absorption bands assigned to polystyrene aromatic group, successively observed at 3050, 1600 and $1494 \mathrm{~cm}^{-1}$ together with small aromatic $\mathrm{CH}$ deformation bands at 698 and $750 \mathrm{~cm}^{-1}$, respectively. The bands at 810 and $820 \mathrm{~cm}^{-1}$ are due to the di-substituted benzene ring of DVB crosslinks. In the sulfonated membrane (spectrum C), the absorption bands, respectively observed at 1123 and 1003 $\mathrm{cm}^{-1}$ were assigned to $\mathrm{SO}_{3}^{-}$groups, while the bands detected at 1300 and 1160 $\mathrm{cm}^{-1}$ were due to $\mathrm{S}=\mathrm{O}$ stretching vibration. The broad band at $3200-3600 \mathrm{~cm}^{-1}$ was due to the $\mathrm{OH}$ groups of water molecules strongly bound to $\mathrm{SO}_{3}^{-}$groups by hydrogen bonding. The characteristic absorption bands of aromatic groups were obscured in the adsorbent spectrum due to the strong intensity of the sulfonic groups and their hydration spheres. These results provide a convincing evidence of successful formation of sulfonated crosslinked polystyrene grafts in PE film.

A tentative molecular structure of DVB crosslinked PE- $g$-PSSA adsorbent is shown in Fig. 2. The physico-chemical properties of the obtained crosslinked PE-g-PSSA adsorbent are listed in Table 1.

\section{Effect of contact time}

Fig. 3 shows the time courses of adsorption of $\mathrm{Ni}(\mathrm{II}), \mathrm{Co}(\mathrm{II}), \mathrm{Pb}(\mathrm{II}), \mathrm{Cu}(\mathrm{II})$ and $\mathrm{Ag}(\mathrm{I})$ on crosslinked PE-g-PSSA adsorbent. As can be seen, the adsorption capacity increased as time increased with a rapid adsorption kinetics achieved within the first $15 \mathrm{~min}$ and the adsorption equilibrium of all metal ions was attained within 30 minutes. The metal adsorption capacities at equilibrium were found to be $68.0,65.0,61.0,55.0$ and $49.0 \mathrm{mg} / \mathrm{g}$ for $\mathrm{Co}(\mathrm{II}), \mathrm{Ni}(\mathrm{II}), \mathrm{Cu}(\mathrm{II})$, $\mathrm{Pb}(\mathrm{II})$ and $\mathrm{Ag}(\mathrm{I})$, respectively. Accordingly, the optimum equilibration time was set at 30 minutes in other experiments conducted to investigate the rest of parameters.

Since, kinetics in a chelating polymer are not only relaying on the availability of ion exchange functional groups but also on their accessibility by counter ions without a steric hindrance, which is greatly determined by the polymeric matrices characteristics [17], the rapid metal adsorption kinetics displayed by crosslinked PE-g-PSSA adsorbent can be attributed to the high concentration of sulfonic acid groups $(2.7 \mathrm{mmol} / \mathrm{g})$, which renders the membrane strongly hydrophilic. As a result the interaction with the metal ions (counter ions) by electrostatic attraction is facilitated with the increase of ions solvation. This behavior is similar to that of Nafion 117 membrane, a commercially available ion exchange membrane containing sulfonic acid groups widely used in fuel cells and chloro-alkali industry, when tested under same test conditions [18]. A longer equilibrium time of 70 minutes was reported for the adsorption of $\mathrm{Cu}(\mathrm{II})$ and $\mathrm{Pb}$ (II) and 60 minutes for the adsorption of $\mathrm{Ni}(\mathrm{II})$ on commercial sulfonic acid containing-cation exchange resins (Dowx 50W) at initial concentrations of $0.1 \mathrm{mg} / \mathrm{L}$ and $\mathrm{pH}$ of 8 [19]. Despite the short time required to attain ion exchange equilibrium for $\mathrm{Co}(\mathrm{II}), \mathrm{Ni}(\mathrm{II}), \mathrm{Cu}(\mathrm{II}), \mathrm{Pb}(\mathrm{II})$ and $\mathrm{Ag}(\mathrm{I})$ ions into crosslinked PE- $g$-PSSA adsorbent film in this study, the adsorption behavior seems to be suitable from kinetic considerations as it is comparable with the results stated in the literature where time required to attain equilibrium with similar resins ranged from $30 \mathrm{~min}$. to $7 \mathrm{~h}[20,21]$.

To elucidate the kinetics of the adsorption of $\mathrm{Co}(\mathrm{II}), \mathrm{Ni}(\mathrm{II}), \mathrm{Cu}(\mathrm{II}), \mathrm{Pb}(\mathrm{II})$ and $\mathrm{Ag}(\mathrm{I})$ on PE- $g$-PSSA adsorbent, a simple pseudo-first order kinetic model represented by the Lagergren equation [22] was used to fit the adsorption data taking into consideration that the adsorption of heavy metals from liquid phase to solid phase is a reversible reaction with an equilibrium being established between two phases [23]:

$$
\log \left(q_{e}-q\right)=\log q_{e}+k_{1} \frac{t}{2.303}
$$

where, $k_{1}$ is the calculated rate constant of adsorption, $q$ and $q_{e}$ are the amounts of metal adsorbed $(\mathrm{mg} / \mathrm{g})$ at a time $t$ and at equilibrium time (min.), respectively.

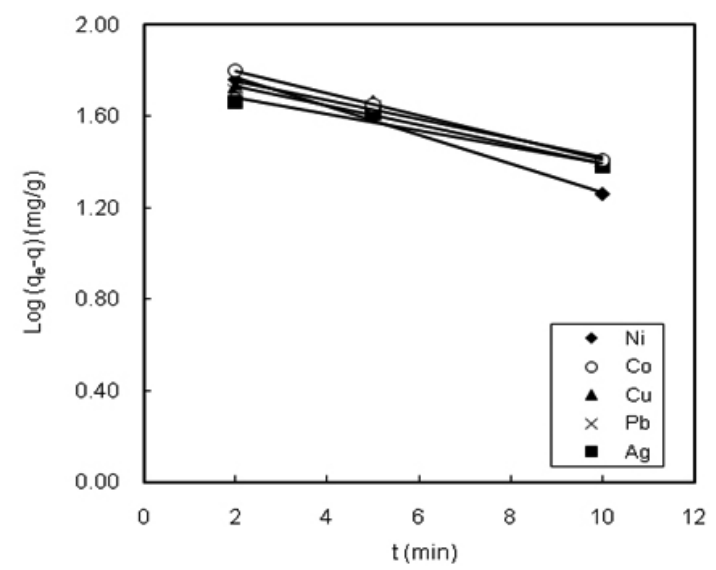

Fig. 4: Pseudo-first order kinetic fitting for the adsorption of Ni (II), $\mathrm{Co}(\mathrm{II}), \mathrm{Cu}(\mathrm{II}), \mathrm{Pb}(\mathrm{II})$, and $\mathrm{Ag}(\mathrm{I})$ ions on crosslinked PE-g-PSSA adsorbent.

Similarly, the data was also fitted to pseudo-second order kinetic given below to determine the rate constant of adsorption $\left(k_{2}\right)$ and the amount of metal adsorbed at equilibrium [24]

$$
\frac{t}{q}=\frac{1}{k_{2} q_{e}^{2}}+\frac{t}{q_{e}}
$$




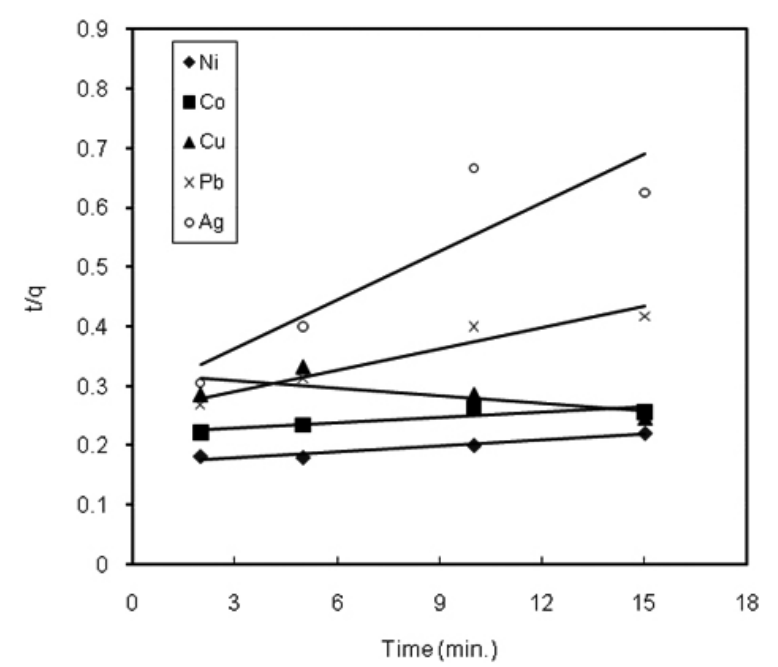

Fig. 5: Pseudo-second order kinetic fitting for the adsorption of $\mathrm{Ni}$ (II), $\mathrm{Co}(\mathrm{II}), \mathrm{Cu}(\mathrm{II}), \mathrm{Pb}(\mathrm{II})$, and $\mathrm{Ag}(\mathrm{I})$ ions on crosslinked PE- $g$-PSSA adsorbent.

Table 2: Data of pseudo-first order kinetic model for adsorption of Ni(II), $\mathrm{Co}(\mathrm{II}), \mathrm{Cu}(\mathrm{II}), \mathrm{Pb}(\mathrm{II})$ and $\mathrm{Ag}(\mathrm{I})$ ions on crosslinked PE-g-PSSA adsorbent.

\begin{tabular}{|c|c|c|c|c|}
\hline Metal ions & $k_{l}$ & $\begin{array}{c}q_{e}(\mathrm{mg} / \mathrm{g}) \\
\text { Experimental }\end{array}$ & $q_{e}(\mathrm{mg} / \mathrm{g})$ Calculated & $R^{2}$ \\
\hline $\mathrm{Ni}(\mathrm{II})$ & 0.063 & 68 & 79 & 0.996 \\
\hline $\mathrm{Co}(\mathrm{II})$ & 0.048 & 65 & 72 & 0.999 \\
\hline $\mathrm{Cu}(\mathrm{II})$ & 0.042 & 61 & 65 & 0.968 \\
\hline $\mathrm{Pb}(\mathrm{II})$ & 0.039 & 56 & 63 & 0.962 \\
\hline $\mathrm{Ag}(\mathrm{I})$ & 0.036 & 49 & 57 & 0.955 \\
\hline
\end{tabular}

Table 3: Data of pseudo-second order kinetic model for adsorption of $\mathrm{Ni}(\mathrm{II}), \mathrm{Co}(\mathrm{II}), \mathrm{Cu}(\mathrm{II}), \mathrm{Pb}(\mathrm{II})$ and $\mathrm{Ag}(\mathrm{I})$ ions on crosslinked PE-g-PSSA adsorbent.

\begin{tabular}{|c|c|c|c|c|}
\hline Metal ions & $k_{2}$ & $\begin{array}{c}q_{e}(\mathrm{mg} / \mathrm{g}) \\
\text { Experimental }\end{array}$ & $\begin{array}{c}q_{e}(\mathrm{mg} / \mathrm{g}) \\
\text { Calculated }\end{array}$ & $R^{2}$ \\
\hline $\mathrm{Ni}(\mathrm{II})$ & 0.0033 & 68 & 89 & 0.80 \\
\hline $\mathrm{Co}(\mathrm{II})$ & 0.0029 & 65 & 78 & 0.92 \\
\hline $\mathrm{Cu}(\mathrm{II})$ & 0.0043 & 61 & 46 & 0.48 \\
\hline $\mathrm{Pb}(\mathrm{II})$ & 0.0120 & 56 & 59 & 0.76 \\
\hline $\mathrm{Ag}(\mathrm{I})$ & 0.0720 & 49 & 58 & 0.93 \\
\hline
\end{tabular}

Figs. 4 and 5 show pseudo-first order and pseudo-second order kinetics of adsorption of $\mathrm{Ni}(\mathrm{II}), \mathrm{Co}(\mathrm{II}), \mathrm{Cu}(\mathrm{II}), \mathrm{Pb}(\mathrm{II})$ and $\mathrm{Ag}(\mathrm{I})$ on crosslinked PE$g$-PSSA adsorbent. The slope and intercepts of linear plots of $\log (q-q)$ vs. $t$ (Fig. 4) and $t / q$ versus $t$ (Fig. 5) were used to respectively, obtain the values of ( $k_{1}$ and $k_{2}$ ) and $q_{e}$ together with the linear correlation coefficients $\left(R^{2}\right)$ and the obtained kinetics data are presented in Tables 2 and 3 respectively.

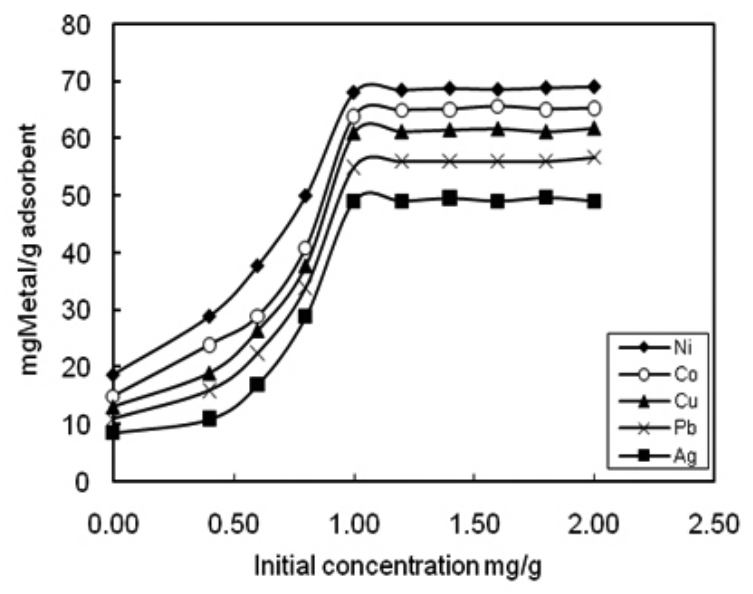

Fig. 6: The effect of initial concentration on the adsorption capacity of heavy metal ions on crosslinked PE- $g$-PSSA adsorbent. Adsorption conditions: contact time, $30 \mathrm{~min}$.; adsorption medium volume, $100 \mathrm{ml}$; agitation rate, 600 $\mathrm{rpm}$; temperature $25^{\circ} \mathrm{C}$ and $\mathrm{pH}, 6.6$.

In pseudo-first order reaction, the calculated $q_{e}$ for all investigated metals were found to be at bar with their corresponding experimental $(q)$ values, $k$ values were found to be in the range of 6.3-3.6 $\times 10^{-2}$ and $R^{2}$ values were found to be close to 1 . On contrary, pseudo-second-order reaction data reveals that $k_{2}$ value are far different from each other and $R^{2}$ values are less close to unity. This suggests that pseudo-first order correlations are more satisfactory than those of pseudo-second order in describing the adsorption kinetics of Ni(II), Co(II), $\mathrm{Cu}(\mathrm{II}), \mathrm{Pb}(\mathrm{II})$ and $\mathrm{Ag}(\mathrm{I})$ on crosslinked PE-g-PSSA adsorbent obtained in this study. This means that the present adsorption systems adhere to the pseudo-first order kinetics, which further suggests that the adsorption rates of $\mathrm{Ni}(\mathrm{II}), \mathrm{Co}(\mathrm{II})$, $\mathrm{Cu}(\mathrm{II}), \mathrm{Pb}(\mathrm{II})$ and $\mathrm{Ag}(\mathrm{I})$ are mainly governed by liquid film diffusion i.e. it is the rate-determining step. This might be casued by presence of the crosslinked structure in the desne PE-g-PSSA adsorbent.

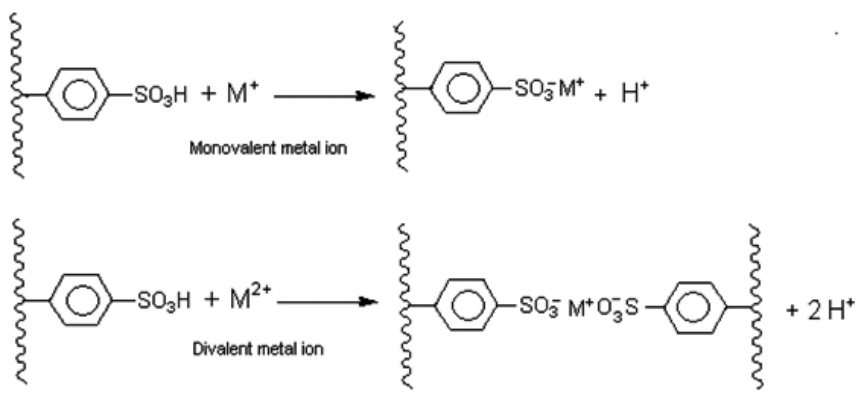

Fig. 7: Schematic representation of ion exchange with monovalent and divalent metal ions in crosslinked PE-g-PSSA adsorbent.

\section{Effect of initial feed concentration}

Fig. 6 shows the variation the adsorption capacity of metal ions with the initial metal ion concentrations in the range of $0.2-2.0 \mathrm{mg} / \mathrm{g}$. Generally, the adsorption capacity increases with the increase in metal ion concentration in the adsorption medium and achieves a plateau at a concentration of $1.0 \mathrm{mg} / \mathrm{g}$ for all metal ions despite the variation of the equilibrium adsorption capacity values from one metal to another. For instance, Ni (II) showed the highest metal adsorption capacity $(68.2 \mathrm{mg} / \mathrm{g})$ while $\mathrm{Ag}(\mathrm{I})$ recorded the lowest value $(49.9 \mathrm{mg} / \mathrm{g})$. This behavior can be attributed to the fact that cation affinity in a crosslinked PE-g-PSSA adsorbent is mainly due to the electrostatic interaction between the hydrophilic negatively charged sulfonic acid groups and the positively charged counter metal ions in the aqueous solution. This can be illustrated from the mechanism of adsorption of monovalent and divalent ions in crosslinked PE- $g$-PSSA adsorbent schematized in Fig. 7. The higher the valance of the counter ions, the larger is the electrostatic attraction. Therefore, crosslinked PE-g-PSSA adsorbent tend to prefer counter ions of higher valence such as $\mathrm{Ni}$ (II) over Ag (I). However, larger counter ions are most likely 
forming ionic clusters of lower water content since the water content of ionic cluster in the adsorbent film is reported to decrease as the size of the counter ions increases [25]. From these results, it can be concluded that the metal ion adsorption on crosslinked PE- $g$-PSSA adsorbent is highly dependent on the initial concentration within the range of $0.2-1.0 \mathrm{mg} / \mathrm{L}$. Moreover, the order of the affinity of the metal ion towards the adsorbent is in the sequence of $\mathrm{Ag}(\mathrm{I})<$ $\mathrm{Pb}(\mathrm{II})<\mathrm{Cu}(\mathrm{II})<\mathrm{Co}(\mathrm{II})<\mathrm{Ni}(\mathrm{II})$.

Table 4: The percentage of adsorption of $\mathrm{Ni}(\mathrm{II}), \mathrm{Co}(\mathrm{II}), \mathrm{Cu}(\mathrm{II}), \mathrm{Pb}$ (II) and $\mathrm{Ag}(\mathrm{I})$ ions on crosslinked PE-g-PSSA adsorbent.

\begin{tabular}{|c|c|c|c|c|c|}
\hline \multirow{2}{*}{$\begin{array}{c}\text { Initial metal } \\
\begin{array}{c}\text { concentration } \\
(\mathrm{mg} / \mathrm{g})\end{array}\end{array}$} & $\mathrm{Ni}(\mathrm{II})$ & $\mathrm{Co}(\mathrm{II})$ & $\mathrm{Cu}(\mathrm{II})$ & $\mathrm{Pb}(\mathrm{II})$ & $\mathrm{Ag}(\mathrm{I})$ \\
\cline { 2 - 6 } & 99.0 & 97.2 & 93.0 & 89.8 & 79.6 \\
\hline 1.0 & 96.8 & 94.9 & 90.0 & 72.6 & 71.4 \\
\hline 0.8 & 91.6 & 89.7 & 83.2 & 68.9 & 59.7 \\
\hline 0.6 & 86.2 & 79.4 & 70.2 & 61.1 & 43.6 \\
\hline 0.4 & 82.2 & 77.4 & 67.2 & 56.7 & 37.9 \\
\hline 0.2 & & & & & \\
\hline
\end{tabular}

Adsorption conditions: initial concentration of metal ions, $1.0 \mathrm{mg} / \mathrm{L}$; volume of adsorption medium, $100 \mathrm{ml}$; agitation rate, $600 \mathrm{rpm}$; $\mathrm{pH}, 6.6$; temperature, $25^{\circ} \mathrm{C}$ and adsorption time, $30 \mathrm{~min}$.

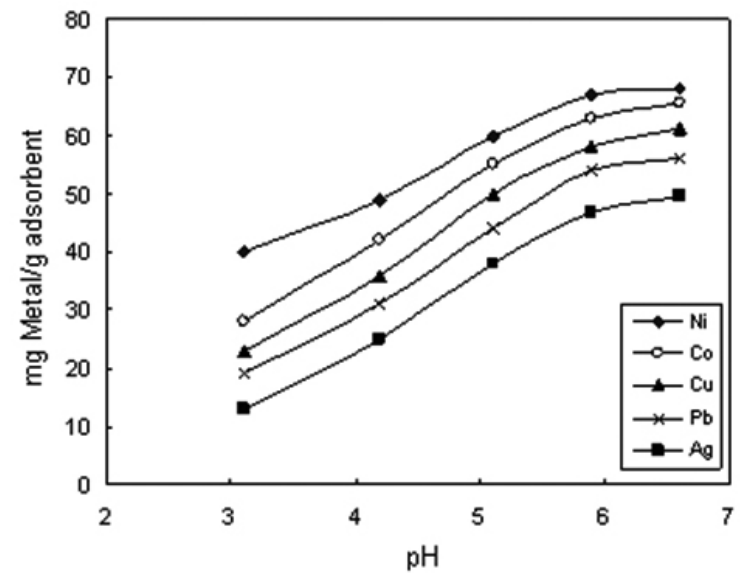

Fig. 8: The effect of $\mathrm{pH}$ of adsorption medium on the adsorption capacity of heavy metal ions on crosslinked PE- $g$-PSSA adsorbent. Adsorption conditions: contact time, $30 \mathrm{~min}$; ; adsorption medium volume, $100 \mathrm{ml}$; agitation rate, 600 rpm and temperature $25^{\circ} \mathrm{C}$.

Table 4 presents the percentage of adsorption of $\mathrm{Ni}(\mathrm{II}), \mathrm{Co}(\mathrm{II}), \mathrm{Cu}(\mathrm{II})$, $\mathrm{Pb}(\mathrm{II})$, and $\mathrm{Ag}(\mathrm{I})$ ions on crosslinked PE-g-PSSA adsorbent. The percentage of adsorption was found to increase with the increase in the initial heavy metal concentration in the range of $0.2-1.00 \mathrm{mg} / \mathrm{L}$. All metal ions recorded their highest metal uptake at a concentration of $1.0 \mathrm{mg} / \mathrm{L}$ with the maximum recovery obtained for $\mathrm{Ni}$ (II) (99.0\%) followed by Co(II) (97.2\%), Cu(II) (93\%) and $\mathrm{Pb}$ (II) $(89.8 \%)$, respectively. $\mathrm{Ag}$ (I) recorded the lowest recovery of $79.6 \%$ at the same metal ion concentration. These results suggest that crosslinked PE$g$-PSSA adsorbent is most effective for removal of $\mathrm{Ni}$ (II), $\mathrm{Co}(\mathrm{II})$ and $\mathrm{Cu}(\mathrm{II})$ at initial feed concentrations in the range of 0.6 to $1.0 \mathrm{mg} / \mathrm{L}$.

\section{Effect of $p H$}

The effect of $\mathrm{pH}$ on the adsorption capacity of heavy metal ions on crosslinked PE-g-PSSA adsorbent was evaluated by adjusting the initial $\mathrm{pH}$ of the solution in the range of 3.1-6.6 and the obtained data was plotted in Fig. 9 . As can be seen, the metal adsorption capacity increases with the increase in $\mathrm{pH}$ in all metal ions solution and reaches their maximum values at $\mathrm{pH}$ of 6.6 with the adsorption efficiency ( $\%$ adsorption) increases in sequence of $\mathrm{Ni}(\mathrm{II})>$ $\mathrm{Co}$ (II) $>\mathrm{Cu}$ (II) $>\mathrm{Pb}$ (II) $>\mathrm{Ag}$ (I). Therefore, the $\mathrm{pH}$ of adsorption medium for the experimental investigation with other parameters was set at 6.6 for all heavy metals.

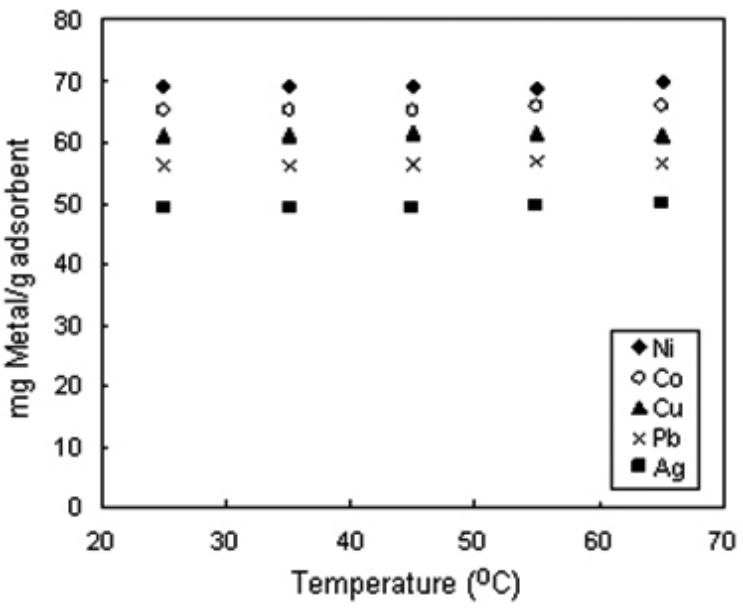

Fig. 9: The effect of temperature on the adsorption capacity of heavy metal ions on crosslinked PE- $g$-PSSA adsorbent. Adsorption conditions: initial concentration, $1.0 \mathrm{mg} / \mathrm{L}$. Contact time, $30 \mathrm{~min}$.; adsorption medium volume, $100 \mathrm{ml}$; agitation rate, $600 \mathrm{rpm}$; temperature $25^{\circ} \mathrm{C}$ and $\mathrm{pH}, 6.6$.

The low adsorption capacity of all metals ions at low pH i.e. 3.1 can be ascribed to competitive adsorption of hydronium $\left(\mathrm{H}_{3} \mathrm{O}^{+}\right)$ions and metal ions for the same active adsorption sites. As the $\mathrm{pH}$ increases, the adsorption zones tend to attain less positivity leading to an increase in electrostatic attraction between the metal ions and sulfonic acid groups. This behavior may be attributed to the electrostatic effects that cause the adsorption capacity to increase with the decrease in the radius of hydrated metal ions, which changes (in present case) in the sequence of $\mathrm{Ni}(\mathrm{II})<\mathrm{Co}$ (II) $<\mathrm{Cu}$ (II) $<\mathrm{Pb}$ (II) $<\mathrm{Ag}$ (I) . Other sequence for same metals i.e. $\mathrm{Co}(\mathrm{II})<\mathrm{Cu}(\mathrm{II})<\mathrm{Ni}(\mathrm{II})<\mathrm{Pb}$ (II) $<\mathrm{Ag}$ (I) was reported elsewhere [26].

In addition, the increase in the charge of metal ion from monovalence to divalence affects the affinity of crosslinked PE- $g$-PSSA adsorbent as depicted by the low adsorption capacity of $\operatorname{Ag}(\mathrm{I})$ compared to all divalent metals. Similar sulfonic acid membranes and resins showed higher affinity for divalent metal ions than monovalent ones [27-28]. These results emphasize on the role of $\mathrm{pH}$ in improving the efficiency and economics of the ion exchange systems.

\section{Effect of temperature}

Fig. 9 shows the metal adsorption capacity of crosslinked PE- $g$-PSSA adsorbent vs. the temperature of the adsorption medium. As can be obviously seen, the variation of the temperature in range of $25-65^{\circ} \mathrm{C}$ has no significant effect on the metal adsorption as indicated by the tiny changes in the equilibrium adsorption capacity with all tested metal ions. This trend suggests that the mechanism of adsorption associated with the removal of $\mathrm{Ni}(\mathrm{II}), \mathrm{Co}(\mathrm{II}), \mathrm{Cu}(\mathrm{II})$, $\mathrm{Pb}(\mathrm{II})$ and $\mathrm{Ag}(\mathrm{I})$ ions on the crosslinked PE-g-PSSA adsorbent is dominated by physical process involves the electrostatic interaction between the ion in the solution and solid adsorbent, which is usually associated with low adsorption heat [29]. This means that the adsorption process has an exothermic character [30]. Similar behavior was observed for Nafion 117 membrane under similar experimental conditions [18].

Table 5: Langmuir and Freundlich adsorption isotherms constants and relevant correlation coefficients.

\begin{tabular}{|ccccccc|}
\hline \multirow{2}{*}{$\begin{array}{c}\text { Metal } \\
\text { ions }\end{array}$} & \multicolumn{3}{c}{ Langmuir equation } & \multicolumn{4}{c|}{ Freundlich equation } \\
\cline { 2 - 7 } & $\begin{array}{c}q_{\max } \\
(\mathrm{mg} / \mathrm{g})\end{array}$ & $\begin{array}{c}b(\mathrm{~L} / \\
\mathrm{mg})\end{array}$ & $R^{2}$ & $k_{f}$ & $1 / n$ & $R^{2}$ \\
\hline $\mathrm{Ni}(\mathrm{II})$ & 73 & 0.015 & 0.998 & 0.904 & 1.805 & 0.973 \\
$\mathrm{Co}(\mathrm{II})$ & 59 & 0.016 & 0.999 & 1.043 & 1.747 & 0.915 \\
$\mathrm{Cu}(\mathrm{II})$ & 67 & 0.016 & 0.999 & 1.236 & 1.739 & 0.947 \\
$\mathrm{~Pb}(\mathrm{II})$ & 61 & 0.017 & 0.998 & 1.319 & 1.691 & 0.954 \\
$\mathrm{Ag}(\mathrm{I})$ & 53 & 0.018 & 0.999 & 1.605 & 1.642 & 0.966 \\
\hline
\end{tabular}




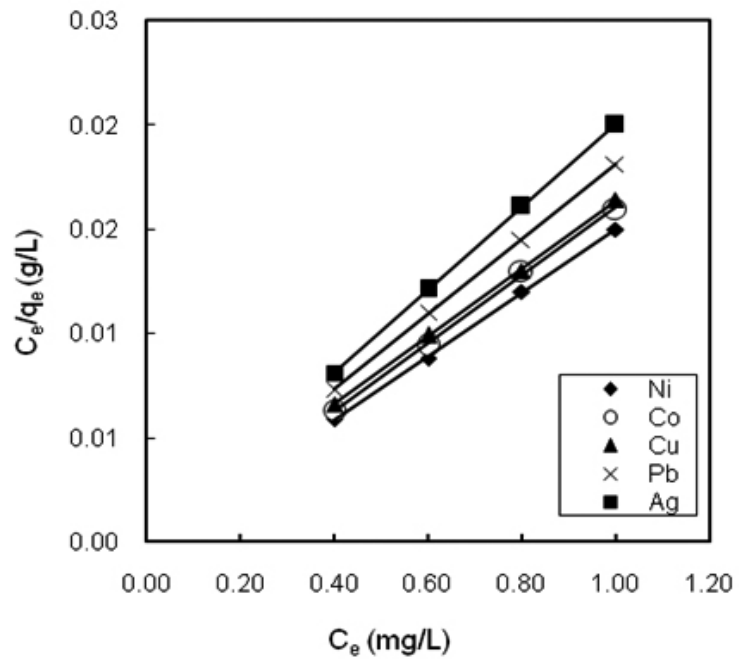

Fig. 9.: Langmuir adsorption isotherms of $\mathrm{Co}$ (II), $\mathrm{Ni}(\mathrm{II}), \mathrm{Cu}(\mathrm{II}), \mathrm{Pb}(\mathrm{II})$, and $\mathrm{Ag}(\mathrm{I})$ ions on crosslinked PE-g-PSSA adsorbent.

\section{Adsorption Isotherm Studies}

The adsorption equilibrium data of $\mathrm{Ni}(\mathrm{II}), \mathrm{Co}(\mathrm{II}), \mathrm{Cu}(\mathrm{II}), \mathrm{Pb}(\mathrm{II})$, and $\mathrm{Ag}$ (I) ions on crosslinked PE- $g$-PSSA adsorbent were used to fit Langmuir and Freundlich isothermal models. The Langmuir equation is based on the assumptions that maximum adsorption corresponds to a saturated monolayer of adsorbate molecules on the adsorbent surface, that the energy of adsorption is constant, and that there is no trans-migration of adsorbate in the plane of the surface [31,32], which is represented by:

$$
q_{e}=\frac{q_{\max } k C_{e}}{1+k C_{e}}
$$

where, $q_{e}$ is the amount adsorbed metal ion at equilibrium $(\mathrm{mg} / \mathrm{g})$, and $k$ is Langmuir constant or the "affinity" parameter $(\mathrm{L} / \mathrm{mg})$, and $q_{\max }$ is the maximum amount of metal ion per weight of the membrane $(\mathrm{mg} / \mathrm{g})$. The linear form of Langmuir adsorption model can be given as [33, 34]:

$$
q_{e}=k_{f} C_{e}^{1 / n}
$$

The isotherm data in Fig. 9 seem to be well described by the linear form of the Langmuir equation. The values of Langmuir adsorption parameters i.e. $q_{\max }$ and $b$ deduced from the slopes and intercepts of the plots together the correlation coefficients $\left(R^{2}\right)$ after linear regression are recorded in Table 5 .

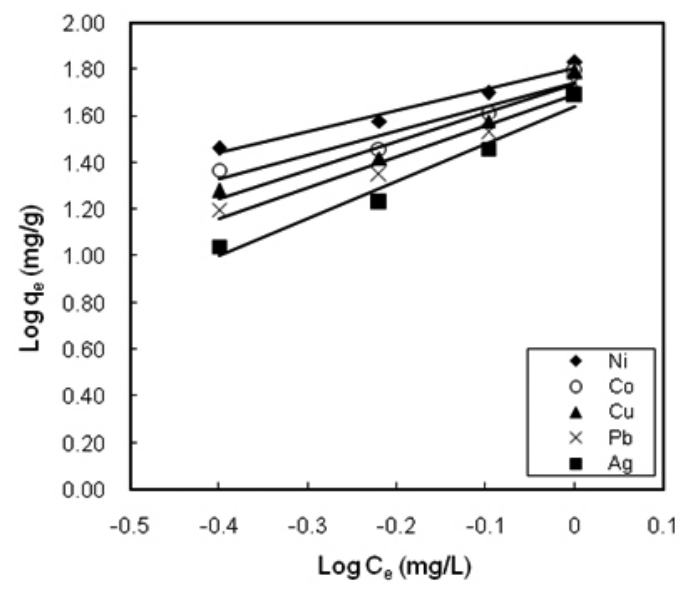

Fig. 10. Freundlich adsorption isotherms of $\mathrm{Ni}(\mathrm{II}), \mathrm{Co}(\mathrm{II}), \mathrm{Cu}(\mathrm{II}), \mathrm{Pb}(\mathrm{II})$, and $\mathrm{Ag}(\mathrm{I})$ ions on crosslinked PE-g-PSSA adsorbent.
The linear relations of $C_{e} / q_{e}$ vs. $C_{e}$ indicate that the adsorption of Ni (II), $\mathrm{Co}(\mathrm{II}), \mathrm{Cu}(\mathrm{II}), \mathrm{Pb}$ (II), and $\mathrm{Ag}(\mathrm{I})$ ions on crosslinked PE-g-PSSA adsorbent films follows Langmuir isotherm model. The high degrees of correlation coefficient $\left(R^{2}\right)$ for the linearized Langmuir relationship suggest a single surface reaction with a constant activation energy is the predominant sorption step.

The Freundlich sorption isotherm is represented by the eqn. [35]:

$$
\frac{C_{e}}{q}=\frac{1}{q_{\max } \cdot b}+\frac{C_{e}}{q_{\max }}
$$

where, $C$ is the equilibrium concentration $(\mathrm{mg} / \mathrm{L})$ and $q$ is the amount adsorbed metal ions at equilibrium $(\mathrm{mg} / \mathrm{g}) . k_{f}$ and $n$ are constants incorporating all parameters affecting the adsorption process such as adsorption capacity and intensity, respectively. The linear form of Freundlich adsorption isotherm was used to evaluate the adsorption data is represented as [36]:

$$
\log q_{e}=\log k_{f}+\frac{1}{n} \log C_{e}
$$

$k_{f}$ and $n$ were calculated from the intercepts and slopes of Freundlich plots shown in Fig. 10 and their values were recorded together with the correlation coefficients $\left(R^{2}\right)$ in Table 4.

Table 6: Data of adsorption/desorption cycles for Ni(II), Co (II), Cu(II), $\mathrm{Pb}$ (II) and $\mathrm{Ag}(\mathrm{I})$ heavy metal ions on crosslinked PE-g-PSSA adsorbent.

\begin{tabular}{|cccccc|}
\hline \multirow{2}{*}{ Cycles } & \multicolumn{5}{c|}{ Amount of adsorbed metal ions (mg/g) } \\
\cline { 2 - 6 } & $\mathrm{Ni}(\mathrm{II})$ & $\mathrm{Co}(\mathrm{II})$ & $\mathrm{Cu}(\mathrm{II})$ & $\mathrm{Pb}(\mathrm{II})$ & $\mathrm{Ag}(\mathrm{I})$ \\
\hline 1 & 68.0 & 65.0 & 61.0 & 55.0 & 49.0 \\
2 & 67.9 & 64.8 & 61.0 & 55.0 & 49.0 \\
3 & 67.9 & 64.7 & 60.9 & 54.8 & 48.7 \\
4 & 67.8 & 64.9 & 60.8 & 55.0 & 48.5 \\
5 & 68.9 & 64.8 & 68.9 & 54.9 & 48.9 \\
\hline
\end{tabular}

Adsorption conditions: initial concentration of metal ions, $1.0 \mathrm{mg} / \mathrm{L}$; volume of adsorption medium, $100 \mathrm{ml}$; agitation rate, $600 \mathrm{rpm}$; $\mathrm{pH}$ 6.6; temperature, $25^{\circ} \mathrm{C}$; adsorption time, $30 \mathrm{~min}$.

Desorption conditions: desorption medium, $0.1 \mathrm{M} \mathrm{HNO}_{3}$; volume of desorption medium, $100 \mathrm{ml}$; desorption time, $16 \mathrm{~h}$ and temperature, $25^{\circ} \mathrm{C}$.

It was reported that $n$ values between 1 and 10 represents a beneficial adsorption [37] and also the values $\mathrm{n}$ and $k$ determine the slope and curvature of the isotherm. Furthermore, the presence of $1 / n$ in values higher than unity is an indication that insignificant adsorption takes place at low concentration but the increase in the amount adsorbed with concentration becomes more significant at higher concentration and vice versa [38]. From the obtained data shown in Table 5 , the value of $1 / n$, which is related to the distribution of bonded ions on the adsorbent surfaces, was found to be less than unity together with the low $k_{f}$ values for the five metal ions adsorption on the membrane indicating unfavorable adsorption.

\section{Desorption of metal ions and reusability}

The reusability of crosslinked PE-g-PSSA adsorbent was tested using adsorption/desorption cycles and the obtained data were presented in Table 6 . The membrane was found to be able to adsorb almost the same amount of metal ions after 5 cycles. This suggests that crosslinked PE- $g$-PSSA adsorbent obtained in this work is a potential ion exchanger for practical use in removal of $\mathrm{Ni}(\mathrm{II}), \mathrm{Co}(\mathrm{II}), \mathrm{Cu}(\mathrm{II}), \mathrm{Pb}(\mathrm{II})$, and $\mathrm{Ag}(\mathrm{I})$ from waste water solutions.

\section{CONCLUSIONS}

The metal ion adsorption capacity (at equilibrium) exerted by DVB crosslinked PE-g-PSSA adsorbent film were found to be 68.0, 65.0, 61.0, 55.0 and $49.0 \mathrm{mg} / \mathrm{g}$ of adsorbent for $\mathrm{Ni}(\mathrm{II}), \mathrm{Co}(\mathrm{II}), \mathrm{Cu}(\mathrm{II}), \mathrm{Pb}(\mathrm{II})$, and $\mathrm{Ag}(\mathrm{I})$, respectively. The adsorption of these metal ions was found dictated by a fast kinetics following the pseudo-first order kinetic model and the obtained data seems to be useful for the designing and fabrication of membrane wastewater treatment systems. The metal ion adsorption on the adsorbent film was found to be highly dependent on the initial concentration and $\mathrm{pH}$ of the medium with $\%$ adsorption maxima of $99,97.2,93,89.8$ and $79.7 \%$ could be achieved at concentrations of $1.0 \mathrm{mg} / \mathrm{L}$ and $\mathrm{pH}$ of 6.6 for $\mathrm{Ni}(\mathrm{II}), \mathrm{Co}(\mathrm{II}), \mathrm{Cu}(\mathrm{II}), \mathrm{Pb}(\mathrm{II})$, 
and $\mathrm{Ag}(\mathrm{I})$, respectively. Unlikely, the adsorption of $\mathrm{Ni}(\mathrm{II}), \mathrm{Co}(\mathrm{II}), \mathrm{Cu}(\mathrm{II})$, $\mathrm{Pb}(\mathrm{II})$, and $\mathrm{Ag}(\mathrm{I})$ was found to be independent of temperature of the solution as it remains closed to $68.0,65.0,61.0,55.0$ and $49.0 \mathrm{mg} / \mathrm{g}$ of adsorbent, respectively. The adsorption equilibrium data of all metal ions was found to fit Langmuir isotherm model more than Freundlich isotherm model. The obtained equilibrium and kinetic data reveals that a single surface reaction with a constant activation energy is the predominant sorption step and the adsorption rate is apparently controlled by the liquid film diffusion process. Finally, the crosslinked PE- $g$-PSSA adsorbent obtained in this work has a potential application for the removal/recovery of $\mathrm{Ni}(\mathrm{II}), \mathrm{Co}(\mathrm{II}), \mathrm{Cu}(\mathrm{II}), \mathrm{Pb}(\mathrm{II})$, and $\mathrm{Ag}(\mathrm{I})$ ions from their waste water solutions.

\section{ACKNOWLEDGEMENT}

The authors wish to acknowledge the financial support obtained from Malaysian Ministry of Science, Technology and Innovation (MOSTI) under since fund program (Grant No. 79283).

\section{REFERENCES}

[1] S. Babel, T. A. Kurniawan, J. Hazard. Mater., 97, 219 (2003).

[2] A. Demirbas, J. Hazard. Mater.157, 220 (2008).

[3] T. A. Kurniawan, G.Y.S. Chan, W. H. Lo, S. Babel, Chem. Eng. J. 118, $83(2006)$

[4] V.K. Gupta, P.J.M. Carrott, M.M.L. Crit. Rev. Environ. Sci Technol., $39,1(2009)$.

[5] A. Dabrowski, Z. Hubicki, P. Podkoscielny, E. Robens, Chemosphere $56,91(2004)$

[6] M. M. Nasef, Grafting and crosslinking of polymers, A. Battacharya, J.W. Rawlins, P. Ray, Eds. John Wiley and Sons, New Jersey, USA, 2008, pp.

[7] S.-H. Choi, Y.C. Nho, G.,-T. Kim, J. Appl. Polym. Sci. 71, 641(1999).

[8] S. - H. Choi, Y.C. Nho, J. Appl. Polym. Sci. 71, 999 (1999).

[9] M. M. Nasef, E.A. Hegazy, Progr. Polym. Sci. 29, 499 (2004).

[10] J. Zu, L. Tong, X. Liu, G. Sun J. Appl. Polym. Sci. 107, 1252 (2008).

[11] A. El-Hag Ali, H.A. Shawky, M.H. El-Sayed, Sep. purify. Techn. 63, 69 (2008).

[12] N. Maziad, S. Abo-Farha, L. Ismail, J. Macromol. Sci. Part: A Pure Appl. Chem. 46 821(2009).
[13] Z. Ajji, A.M. Ali, J. Hazard. Mater. 173, 71 (2010).

[14] M. M. Nasef, H. Saidi, H. M. Nor, K. M. Dahlan, K. Hashim, Malaysian J. Nucl. Sci. 1, 55 (1999).

[15] M. M. Nasef, H. Saidi, H. M. Nor, K. M. Dahlan, K. Hashim, Malaysian J. Nucl. Sci. 18, 47 (2000).

[16] M. M. Nasef, H. Saidi, Inter. J. Polym. Mater. 53, 1 (2004).

[17] G. Kantipuly, S. Katragadda, A. Chow H.D. Gesser, Talanta 37, 491 (1990).

[18] M.M. Nasef, A.H. Yahaya, Desalination, 249, 677 (2009).

[19] E. Pehlivan, T. Altun, J. Hazard. Mater. B 134, 149 (2006).

[20] A. Denizli, D. Tanyolac, B. Salih, A. Ozdural, J. Chromatogr. A 793, 47 (1998).

[21] M.D. Osborne, H.H. Girault , J. Electroanal. Chem. 370, 287 (1994).

[22] K. Periyasamy, C. Namasivayam, Ind. Eng. Chem Res.33, 317 (1994).

[23] Y. Orhan, H. Bugukgungor, Water Sci. Technol .28, 247 (1993).

[24] B. Alyüz, S. Veli, J. Hazard. Mater. 167, 482 (2009).

[25] K.-L Huang, T. M. Holsen, J. R. Selman, J. Membr. Sci. 210, 137 (2002).

[26] E. R. Nightingale, J. Phys. Chem. 63, 1381 (1959).

[27] A. Chapotot, G. Pourcelly, C. Gavach, J. Membr. Sci. 96, 167 (1994).

[28] A. Demirbas, E. Pehlivan, F. Gode, T. Altun, G. Arslan, J. Coll. Inter. Sci. 282, 20 (2005).

[29] I. Kula, M. Ugurlu, H. Karaoglu, A. Celik, Bioresour. Technol. 99, 492 (2008).

[30] N. Azouaou, Z. Sadaoui, A. Djaafri, H. Mokaddem, J. Hazard. Mater. $184,126(2010)$.

[31] I. Langmuir, J. Amer. Chem. Soc. 38, 2221 (1916).

[32] Z. Samczynski, R. Dybczynski, J. Chromatogr. A 789, 157 (1997).

[33] M. Yu, W. Tian, D. Sun, W. Shen, G. Wang, N. Xu, Anal. Chim. Acta 428, 209-218.

[34] R. Jalali, H. Ghafourian, Y. Asef, S.J. Davarpanah, S. Sepehr, J. Hazard Mater. 92, 253 (2002)

[35] H. Freundlich, Z. Phys. Chem, 57, 385 (1906)

[36] M.M. Rao, D.H.K.K. Reddy, P. Venkateswarlu, K. Seshaiah, J. Environ. Manage. 90634 (2009).

[37] K. Kadirvelu, C. Namasivayam, Environ. Technol. 21, 1091 (2000).

[38] T. Hsisheng, H. Chien-To, Ind. Eng. Chem. Res. 39, 3618 (1998). 